INTERVENTIONAL CARDIOLOGY AND SURGERY

\title{
C Reactive protein, moderate alcohol consumption, and long term prognosis after successful coronary stenting: four year results from the GENERATION study
}

\author{
M N Zairis, J A Ambrose, A G Lyras, M A Thoma, P K Psarogianni, G P Psaltiras, A D Kardoulas, \\ G P Bibis, E G Pissimissis, P C Batika, M C DeVoe, A A Prekates, S G Foussas, on behalf of the \\ GENERATION Study Group
}

Heart 2004;90:419-424. doi: 10.1136/hrt.2003.016337

See end of article for authors' affiliations

Correspondence to: Dr Michael N Zairis, 273277 Alkiviadou Street, Piraeus 18536, Greece; zairis@hellasnet.gr

Accepted 27 October 2003

\begin{abstract}
Objectives: To determine the impact of moderate alcohol consumption on long term prognosis after successful coronary stenting, and whether it could be related to preprocedural plasma $C$ reactive protein (CRP).

Design: Part of the prospectively designed GENERATION study which investigated the impact of several biochemical factors, including plasma CRP, on long term prognosis after coronary stenting.

Setting: Tertiary referral centre.

Patients: 483 consecutive patients with stable or unstable coronary artery disease who underwent successful coronary stenting and were followed for up to four years. Information about alcohol consumption was collected prospectively.

Interventions: Successful coronary stenting.

Main outcome measures: The incidence of the composite end point of readmission to hospital for unstable angina, non-fatal myocardial infarction, or cardiac death, whichever occurred first.

Results: By the end of follow up the incidence of the composite end point was $22.8 \%$. Patients with a baseline plasma CRP concentration of $<0.68 \mathrm{mg} / \mathrm{dl}$ (defined by ROC analysis) did not show any difference in the composite end point $(p=0.9)$ or its components, regardless of the amount of alcohol consumed during follow up. However, among patients with plasma CRP concentration of $\geqslant 0.68 \mathrm{mg} / \mathrm{dl}$, those who drank moderately had a lower incidence of the composite end point $(p<0.001)$ or its components.

Conclusions: Moderate alcohol consumption may have a beneficial impact on the long term prognosis following successful coronary stenting. The extent of this effect is positively related to preprocedural inflammatory status. An anti-inflammatory action of moderate alcohol consumption cannot be excluded.
\end{abstract}

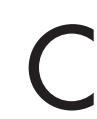
oronary stenting is an established therapeutic approach in patients with coronary artery disease. Although the introduction of new antiplatelet agents has reduced early and late complications substantially, many successfully treated patients still experience late non-fatal or fatal ischaemic events. Several studies have recently shown an incremental role of inflammation in long term prognosis following either simple angioplasty or coronary stenting, and preprocedural high plasma $\mathrm{C}$ reactive protein (CRP) concentrations have been shown to identify a group of patients at increased risk of late ischaemic complications. ${ }^{1-4}$ Moreover, numerous observational studies have consistently shown the beneficial effect of moderate alcohol consumption (one to two drinks a day) on coronary artery disease related mortality, ${ }^{5-12}$ especially in populations at high risk of this condition. ${ }^{810}$ However, data on alcohol consumption and long term prognosis after successful coronary stenting are lacking.

Although several pathophysiological mechanisms have been proposed for the beneficial effect of moderate alcohol consumption on coronary artery disease related mortalityincluding favourable effects on lipids ${ }^{13-16}$ or haemostatic factors ${ }^{17}{ }^{18}$ - these mechanisms have not yet been fully clarified. Given the fact that the beneficial effect of moderate alcohol consumption is greater in populations at high risk of coronary artery disease, ${ }^{8}{ }^{10}$ it was hypothesised that patients at risk of long term ischaemic complication following successful coronary stenting (high preprocedural plasma CRP values) would obtain greater benefit from moderate alcohol consumption than those at low risk (low preprocedural CRP). The GENERATION study (global evaluation of new events and restenosis after stent implantation) afforded us the opportunity to examine the effect of moderate alcohol consumption on long term prognosis after successful coronary stenting, using the patients' preprocedural plasma CRP concentrations.

\section{METHODS}

Study patients

This study was part of the prospectively designed GENERATION study, which investigated the impact of several biochemical factors, including preprocedural plasma concentrations of CRP, on long term morbidity and mortality for up to three years after successful coronary stenting.

Details of the study design, inclusion and exclusion criteria, and the long term results for the first three years of follow up have been published previously. ${ }^{19}$ In summary,

Abbreviations: ANOVA, analysis of variation; $\mathrm{Cl}$, confidence interval; CRP, C reactive protein; HR, hazard ratio; GENERATION, global evaluation of new events and restenosis after stent implantation; $\mathrm{HDL}$, high density lipoprotein; ROC, receiver operated characteristic curve 
Table 1 Baseline clinical characteristics

\begin{tabular}{|c|c|c|c|c|}
\hline & $\begin{array}{l}\text { Group } 1 \\
(n=181)\end{array}$ & $\begin{array}{l}\text { Group } 2 \\
(n=123)\end{array}$ & $\begin{array}{l}\text { Group } 3 \\
(n=170)\end{array}$ & p Value \\
\hline Age (years) & $60(10.2)$ & $59.6(9.8)$ & $58.4(10.2)$ & 0.3 \\
\hline Male sex & $142(78.5 \%)$ & $103(83.7 \%)$ & $143(84.1 \%)$ & 0.3 \\
\hline Hypertension & $83(45.9 \%)$ & $53(43.1 \%)$ & $68(40 \%)$ & 0.5 \\
\hline Current smoking & $117(64.6 \%)$ & $81(65.9 \%)$ & $116(68.2 \%)$ & 0.8 \\
\hline Diabetes mellitus & $41(22.7 \%)$ & $22(17.9 \%)$ & $30(17.6 \%)$ & 0.4 \\
\hline Hypercholesterolaemia & $99(54.7 \%)$ & $68(55.3 \%)$ & $91(53.5 \%)$ & 0.9 \\
\hline Past myocardial infarction* & $14(7.7 \%)$ & $11(8.9 \%)$ & $16(9.4 \%)$ & 0.8 \\
\hline Past coronary angioplasty* & $7(3.9 \%)$ & $5(4.1 \%)$ & $8(4.7 \%)$ & 0.9 \\
\hline $\begin{array}{l}\text { Past bypass surgery* } \\
\text { Admission qualifying event }\end{array}$ & $5(2.8 \%)$ & $4(3.3 \%)$ & $3(1.8 \%)$ & 0.7 \\
\hline Stable angina & $33(18.2 \%)$ & $32(26 \%)$ & $42(24.7 \%)$ & 0.2 \\
\hline NST ACS & 81 (44.8\%) & 48 (39\%) & $62(36.5 \%)$ & 0.3 \\
\hline STE MI & $67(37 \%)$ & $43(35 \%)$ & $66(38.8 \%)$ & 0.8 \\
\hline CRP (mg/dl) & $0.7(0.6)$ & $0.7(0.7)$ & $0.7(0.5)$ & 0.8 \\
\hline \multicolumn{5}{|c|}{$\begin{array}{l}\text { Values are mean (SD) or } \mathrm{n}(\%) \text {. } \\
\text { *History of occurrence six months or more before study. } \\
\text { Group 1, less than one alcoholic drink a week or none; group 2, one to six alcoholic drinks a week; group 3, one to } \\
\text { two alcoholic drinks a day; NST ACS, non-ST elevation acute coronary syndrome; STE MI, ST elevation myocardial } \\
\text { infarction. }\end{array}$} \\
\hline
\end{tabular}

903 consecutive patients who were admitted between January 1998 and April 2000 with a diagnosis of either stable angina, non-ST elevation acute coronary syndrome, or ST elevation myocardial infarction were consider eligible for the study. Among patients with ST elevation infarction, only those who presented within the first six hours of index pain, and among patients with non-ST elevation acute coronary syndrome, only those who presented within 24 hours, were screened and included. Patients with left bundle branch block, infectious or inflammatory disease, malignancy, hepatic dysfunction, plasma creatinine $>133 \mu \mathrm{mol} / \mathrm{l}$ ( $1.5 \mathrm{mg} / \mathrm{dl})$ (the upper normal value), a history of myocardial infarction, coronary revascularisation in the last six months, or a left ventricular ejection fraction of $<35 \%$ before current angioplasty were excluded.

Patients with non-ST elevation acute coronary syndrome or ST elevation myocardial infarction were scheduled for coronary angiography and possible coronary angioplasty beyond the third day of admission and after their initial stabilisation, or earlier if clinically indicated. Of the 903 patients considered, 501 eligible patients underwent coronary angioplasty with stent implantation. We excluded 18 patients who needed urgent coronary surgery, who died in hospital, or who had myocardial infarction in hospital. Thus 483 patients with successful coronary stenting in 539 vessels ( 554 lesions) comprised the study cohort.

The primary end point was the composite of readmission to hospital for unstable angina, non-fatal myocardial infarction, or cardiac death, whichever occurred first. Cardiac death was defined as sudden unexplained death, death from fatal myocardial infarction, or death after readmission to hospital for heart failure or possible acute myocardial ischaemia. New non-fatal myocardial infarction was defined as prolonged angina accompanied by new ECG abnormalities and elevation of creatine kinase-MB (to more than twice normal). New unstable angina was defined as rest angina with new ECG abnormalities without elevation of creatine kinase-MB. The diagnosis of cardiac death, non-fatal myocardial infarction, or unstable angina was verified by death certificates, discharge medical reports, hospital records, new ECGs, or telephone contact with attending physicians.

Patients were followed up clinically at one, three, and six months and subsequently every six months for up to three years. After the end of the third year of follow up, the

Table 2 Baseline angiographic and coronary stenting related data

\begin{tabular}{|c|c|c|c|c|}
\hline & $\begin{array}{l}\text { Group } 1 \\
(n=181)\end{array}$ & $\begin{array}{l}\text { Group 2 } \\
(n=123)\end{array}$ & $\begin{array}{l}\text { Group 3 } \\
(n=170)\end{array}$ & p Value \\
\hline LVEF (\%) & $49.6(7.1)$ & $50(7.6)$ & $50(6.5)$ & 0.8 \\
\hline Multivessel CAD & 73 (40.3\%) & $50(40.7 \%)$ & $56(32.9 \%)$ & 0.3 \\
\hline \multicolumn{5}{|c|}{ Characteristics of the 539 treated vessels } \\
\hline Number of vessels & 205 & 142 & 192 & \\
\hline Left anterior descending & $104(57.5 \%)$ & $77(62.6 \%)$ & $104(61.2 \%)$ & 0.6 \\
\hline Left circumflex & $41(22.7 \%)$ & $21(17.1 \%)$ & $30(17.6 \%)$ & 0.5 \\
\hline Right coronary & $58(32 \%)$ & $42(34.1 \%)$ & $56(32.9 \%)$ & 0.9 \\
\hline Graft & $2(1.1 \%)$ & $2(1.6 \%)$ & $2(1.2 \%)$ & 0.9 \\
\hline \multicolumn{5}{|c|}{ Characteristics of the 554 treated lesions } \\
\hline $\begin{array}{l}\text { Number of lesions } \\
\text { Preprocedurally }\end{array}$ & 212 & 145 & 197 & \\
\hline $\mathrm{B} 2$ or $\mathrm{C}$ & $120(56.9 \%)$ & 78 (53.7\%) & 109 (55.3\%) & 0.9 \\
\hline Lesion stenosis (\%) & $83.4(7.9)$ & $83.2(7.7)$ & $83.2(8.6)$ & 0.9 \\
\hline RLD $(\mathrm{mm})$ & $3.3(0.4)$ & $3.4(0.3)$ & $3.3(0.4)$ & 0.9 \\
\hline MLD (mm) & $0.55(0.27)$ & $0.56(0.27)$ & $0.56(0.31)$ & 0.9 \\
\hline \multicolumn{5}{|l|}{ Postprocedurally } \\
\hline Lesion stenosis (\%) & $8.8(8.7)$ & $9.2(9.1)$ & $7.9(7.8)$ & 0.4 \\
\hline MLD (mm) & $3.16(0.47)$ & $3.12(0.41)$ & $3.17(0.42)$ & 0.7 \\
\hline
\end{tabular}

Values are mean (SD) or $\mathrm{n}(\%)$.

CAD, coronary artery disease; group 1 , less than one alcoholic drink a week or none; group 2, one to six alcoholic drinks a week; group 3, one to two alcoholic drinks a day; LVEF, left ventricular ejection fraction; MLD, minimum lumen diameter; RLD, reference lumen diameter. 


\begin{tabular}{|c|c|c|c|c|}
\hline & $\begin{array}{l}\text { Group } 1 \\
(n=181)\end{array}$ & $\begin{array}{l}\text { Group } 2 \\
(n=123)\end{array}$ & $\begin{array}{l}\text { Group } 3 \\
(n=170)\end{array}$ & $p$ Value \\
\hline Red wine & 88 (78.6\%) & 90 (73.2\%) & $124(72.9 \%)$ & 0.5 \\
\hline White wine & $30(26.5 \%)$ & $28(22.8 \%)$ & $51(30 \%)$ & 0.4 \\
\hline Beer & $42(37.2 \%)$ & $48(39 \%)$ & 73 (42.9\%) & 0.6 \\
\hline Spirits & 19 (16.8\%) & $20(16.3 \%)$ & $30(17.6 \%)$ & 0.9 \\
\hline
\end{tabular}

Values are $\mathrm{n}(\%)$.

Group 1, less than one alcoholic drink a week or none; group 2, one to six alcoholic drinks a week; group 3, one to two alcoholic drinks a day.

GENERATION protocol was amended. Extension of the follow up period to up to five years was included in the protocol amendment. The scientific committee for the study decided to extend the follow up in order to evaluate the consistency of the three year results.

In the original protocol and in the amendment, information on the daily consumption of alcohol during follow up was obtained prospectively. Patients were initially preclassified into four groups according to their self reported alcohol consumption during the follow up period: group 1, less than one alcoholic drink a week or none; group 2, one to six alcoholic drinks a week; group 3, one to two alcoholic drinks a day (moderate alcohol consumption); and group 4, more than two alcoholic drinks a day. Drinking habits were updated during the predefined follow up intervals, and the average daily or weekly alcohol consumption was estimated. However, during follow up, no patient drank more than two alcoholic drinks a day, so the cohort was subsequently reclassified into three groups: group 1, less than one alcoholic drink a week or none; group 2, one to six alcoholic beverages a week; group 3, one to two alcoholic drinks a day (moderate alcohol consumption).

In the present report, the results for the original primary end point during the first four years of the extended follow up are presented. The original and the amended protocols were approved by the local ethics committee, and informed consent was obtained from all participants at the time of recruitment.

\section{CRP assays}

Venous blood samples for biochemical analysis were obtained during screening. All blood samples for CRP were initially analysed using a quantitative turbidimetric method (Dade Behring, Marburg, Germany) with a lower limit of detection at $0.5 \mathrm{mg} / \mathrm{dl}$. Subsequently when a highly sensitive nephelometric analytical method was available (Dade Behring; lower limit of detection, $0.1 \mathrm{mg} / \mathrm{dl}$ ), all deep frozen $\left(-80^{\circ} \mathrm{C}\right)$ stored plasma samples with CRP values of $\leqslant 0.5 \mathrm{mg} / \mathrm{dl}$ were reanalysed.

\section{Statistical analysis}

Values are expressed as mean (SD). Comparisons of continuous variables among the groups were made using analysis of variance (ANOVA) or the Kruskal-Wallis test, as appropriate. Bonferroni adjusted ANOVA, $t$ tests, or MannWhitney U tests were used, as appropriate, for pairwise comparisons between the groups. Associations between two categorical variables were tested using $\chi^{2}$ tests or Fisher's exact tests. Receiver operating characteristic (ROC) curves were constructed for CRP values to determine their accuracy in predicting the primary end point (measured by the area under the ROC curve, range 0.5-1). To avoid arbitrary cut off points of CRP for the prediction of the primary end point, the "optimal" cut off point with the highest predictive accuracy which separated the cohort into two populations was estimated by ROC analysis. Cox's proportional hazards model was used to assess the significance of any difference noted in the incidence of the primary end point or its components among the groups. Event-free survival was analysed using the Kaplan-Meier method, and log rank testing was used for comparisons among the curves.

All tests were two tailed and a probability value of $p<0.05$ was considered significant. Statistical analysis was done with SPSS statistical software (release 10.0, SPSS Inc, Illinois, USA).

\section{RESULTS}

\section{Baseline characteristics}

There were no significant differences in baseline clinical or interventional characteristics or types of alcoholic drink consumed among the three groups (tables 1-3). The majority of the patients with ST elevation myocardial infarction had received intravenous thrombolysis after admission (147 of $177 ; 82.5 \%)$ and five underwent either primary or rescue angioplasty. Twenty five patients with ST elevation myocardial infarction (with a preprocedural left ventricular ejection fraction of $>35 \%$ ) had not received acute reperfusion therapy because there were contraindications. Glycoprotein IIb/IIIa inhibitors were given in $15.8 \%$ of the patients with non-ST elevation acute coronary syndromes.

\section{Long term follow up}

Clinical follow up was obtained in 474 patients (474 of 483; $98.1 \%$ ) at (mean (SD)) 36 (10) months (range 1-50 months); surviving patients were followed up for 38 (10) months
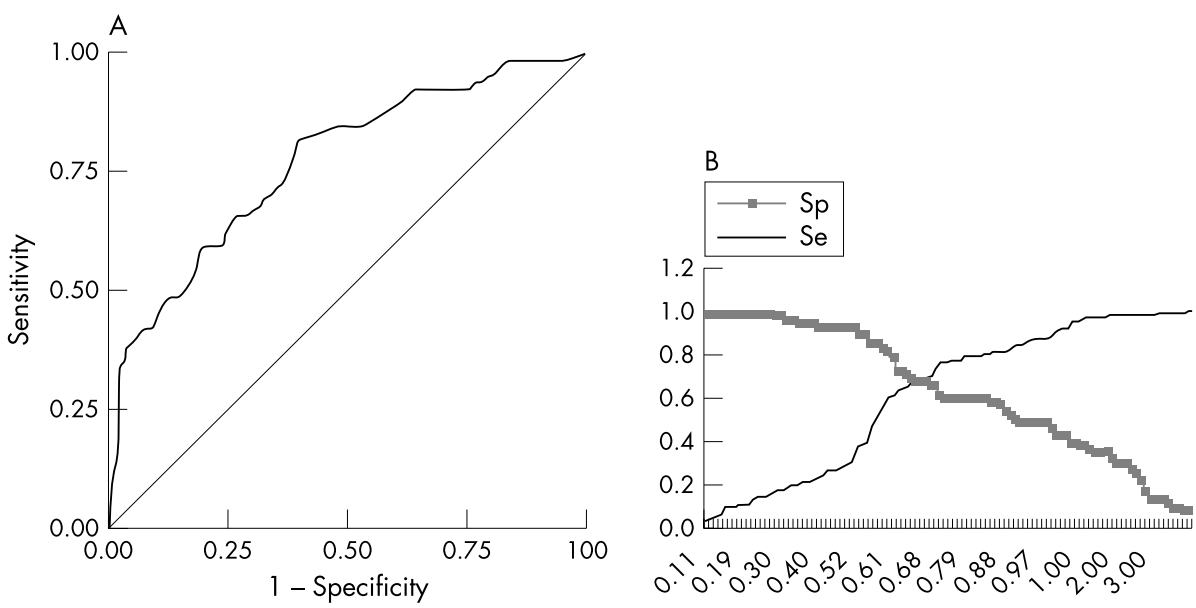

Figure 1 Receiver operating characteristic (ROC) curves of CRP for the composite primary end point $(A)$, and optimal cut off point (B). (ROC area $0.77 ; 95 \% \mathrm{Cl} 0.70$ to 0.83 ; $\mathrm{p}<0.001)$. Se, sensitivity; Sp, specificity. 


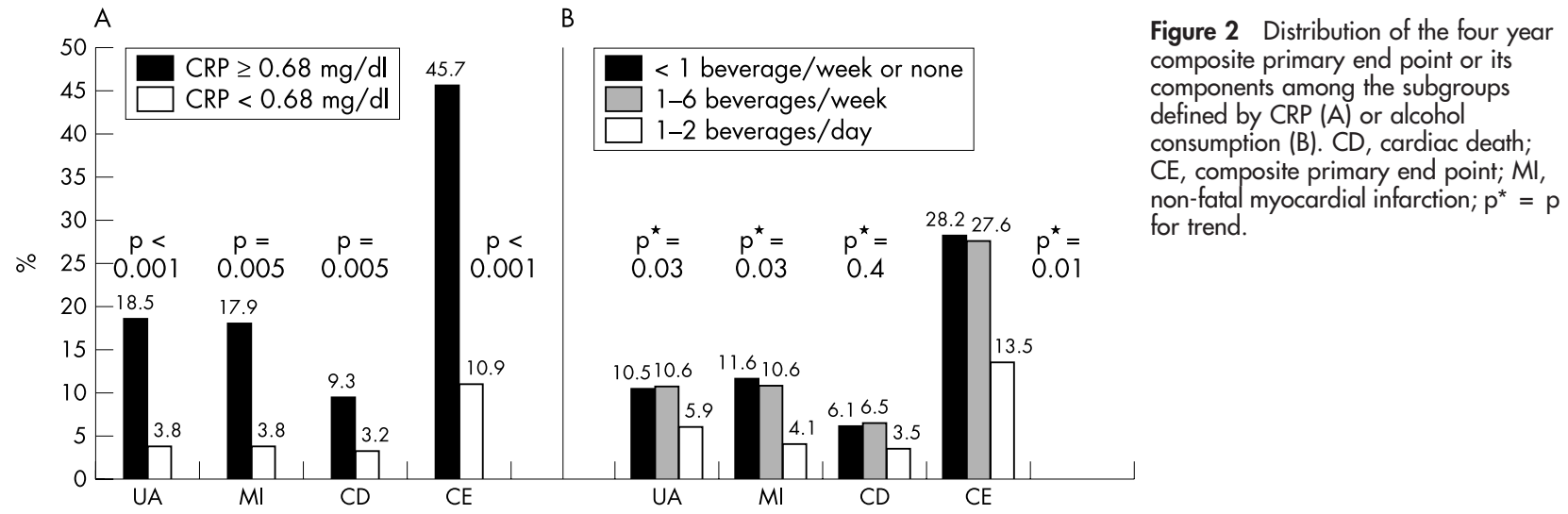

(range 21-50 months). By the end of follow up, 42 patients $(8.2 \%)$ had been readmitted to hospital for unstable angina, $41(8.6 \%)$ suffered a non-fatal myocardial infarct, and 25 $(5.2 \%)$ had died for cardiac reasons. During this period, the patients received several drugs including aspirin, ticlopidine, statins, $\beta$ blockers, calcium channel blockers, and angiotensin converting enzyme inhibitors, with no significant differences among the study groups (data not presented).

\section{CRP and long term prognosis}

ROC analysis indicated that CRP values predicted the composite primary end point reasonably accurately (fig 1A), with an "optimal" cut off point at $0.68 \mathrm{mg} / \mathrm{dl}$ (fig lB). The 164 patients with values of $\geqslant 0.68 \mathrm{mg} / \mathrm{dl}$ were at higher risk for the composite end point (hazard ratio (HR) 5.5, 95\% confidence interval (CI) 3.6 to $8.2 ; \mathrm{p}<0.001$ ) or its components than patients with values of $<0.68 \mathrm{mg} / \mathrm{dl}$ (fig 2A). In particular, the former were at higher risk than the latter for either readmission to hospital for unstable angina (HR 6.1, 95\% CI 3.1 to $11.8 ; \mathrm{p}<0.001$ ), non-fatal myocardial infarction (HR 6.0, 95\% CI 3.1 to 12 ; p $<0.001$ ), or cardiac death (HR 4.0, 95\% CI 1.8 to 8.9; $\mathrm{p}=0.001$ ) (fig 2A).

\section{Alcohol consumption and long term prognosis}

The effect of alcohol on long term prognosis was identical in male and female subjects, and did not vary with the type of drink consumed (data not presented). The distribution of the events according to alcohol consumption during the follow up is presented in fig $2 \mathrm{~B}$. There was no significant difference in the incidence of either the composite end point or its components between groups 1 and 2 . However, patients in group 3 were at lower risk for the composite end point than those in group 2 (HR $0.5,95 \%$ CI 0.3 to $0.8 ; \mathrm{p}=0.004$ ) or group l (HR 0.7, 95\% CI 0.5 to $0.9 ; \mathrm{p}=0.001$ ). In particular, group 3 patients were at lower risk for readmission to hospital for unstable angina (HR $0.5,95 \%$ CI 0.2 to 0.9 ; $\mathrm{p}=0.03$; and 0.7 ( 0.5 to 0.9 ), $\mathrm{p}=0.04$, respectively) than groups II and I; and for non-fatal myocardial infarction (HR $0.4,95 \%$ CI 0.2 to $0.9 ; \mathrm{p}=0.04$; and HR $0.6,95 \%$ CI 0.4 to $0.9 ; \mathrm{p}=0.01)$. However, the risk for cardiac death (HR $0.5,95 \%$ CI 0.2 to $1.5 ; \mathrm{p}=0.3$; and HR $0.7,95 \%$ CI 0.4 to $1.2 ; \mathrm{p}=0.2$ ) was not significantly lower in group 3 patients.

\section{CRP, alcohol consumption, and long term prognosis}

The distribution of the events according to the baseline plasma CRP values and alcohol consumption during follow up is presented in fig 3. Kaplan-Meier curves for the primary composite end point according to the baseline plasma CRP values and alcohol consumption during follow up are presented in fig 4. Among the patients with baseline CRP values of $<0.68 \mathrm{mg} / \mathrm{dl}$ there was no difference in the long term prognosis, regardless to the amount of alcohol consumed (figs $3 \mathrm{~A}$ and $4 \mathrm{~A}$ ). However, among those with baseline CRP values of $\geqslant 0.68 \mathrm{mg} / \mathrm{dl}$, group 3 patients had a significantly lower incidence of the composite end point than group 2 (HR $0.3,95 \%$ CI 0.1 to $0.5 ; \mathrm{p}<0.001$ ) and group 1 (HR $0.5,95 \%$ CI 0.3 to $0.6 ; \mathrm{p}<0.001$ ) (figs $3 \mathrm{~B}$ and $4 \mathrm{~B}$ ). This was true for all components of the composite end point. In particular, group 3 patients were at lower risk for readmission to hospital for unstable angina than groups 2 and 1 patients (HR 0.3, 95\% CI 0.1 to 0.8 ); $\mathrm{p}=0.02$; and HR $0.5,95 \%$ CI 0.3 to $0.8 ; \mathrm{p}=0.008$, respectively), for non-fatal myocardial infarction (HR 0.3, 95\% CI 0.1 to $0.9 ; \mathrm{p}=0.02$; and HR 0.5, $95 \%$ CI 0.3 to 0.8 ), or for cardiac death (HR $0.2,95 \%$ CI 0.1 to $0.7 ; \mathrm{p}=0.002$; and HR $0.4,95 \%$ CI 0.2 to $0.8, \mathrm{p}=0.02$ ) (fig 3B).

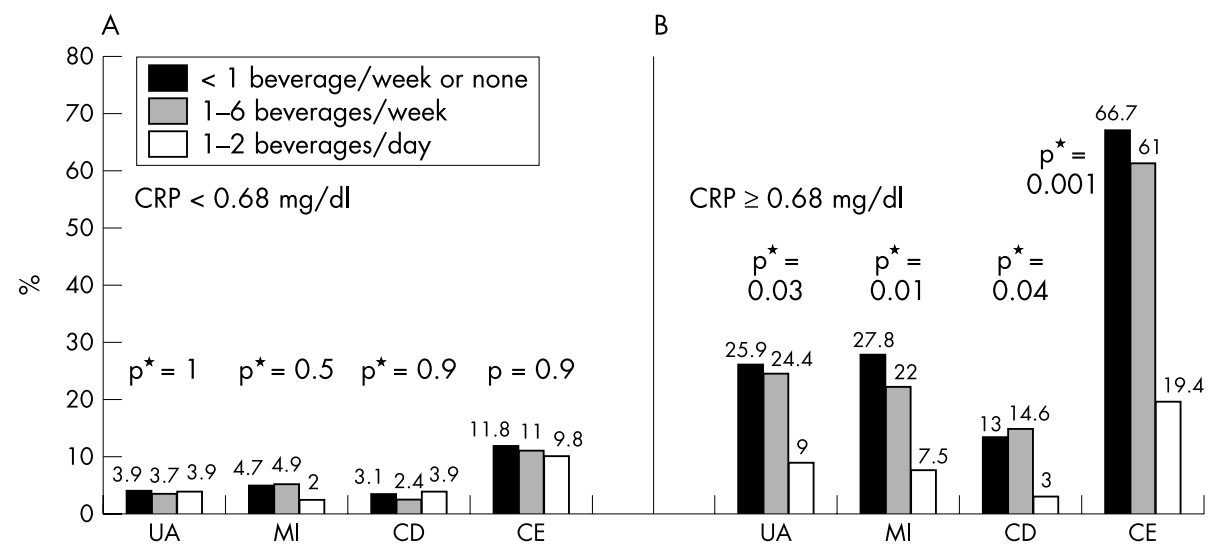

Figure 3 Distribution of the four year composite primary end point or its components among the subgroups defined by alcohol consumption in patients with CRP concentrations of $<0.68 \mathrm{mg} / \mathrm{dl}(\mathrm{A})$ or $\geqslant 0.68 \mathrm{mg} / \mathrm{dl}$ (B). $C D$, cardiac death; $C E$, composite primary end point; $\mathrm{Ml}$, non-fatal myocardial infarction; $\mathrm{p}^{*}=\mathrm{p}$ for trend. 

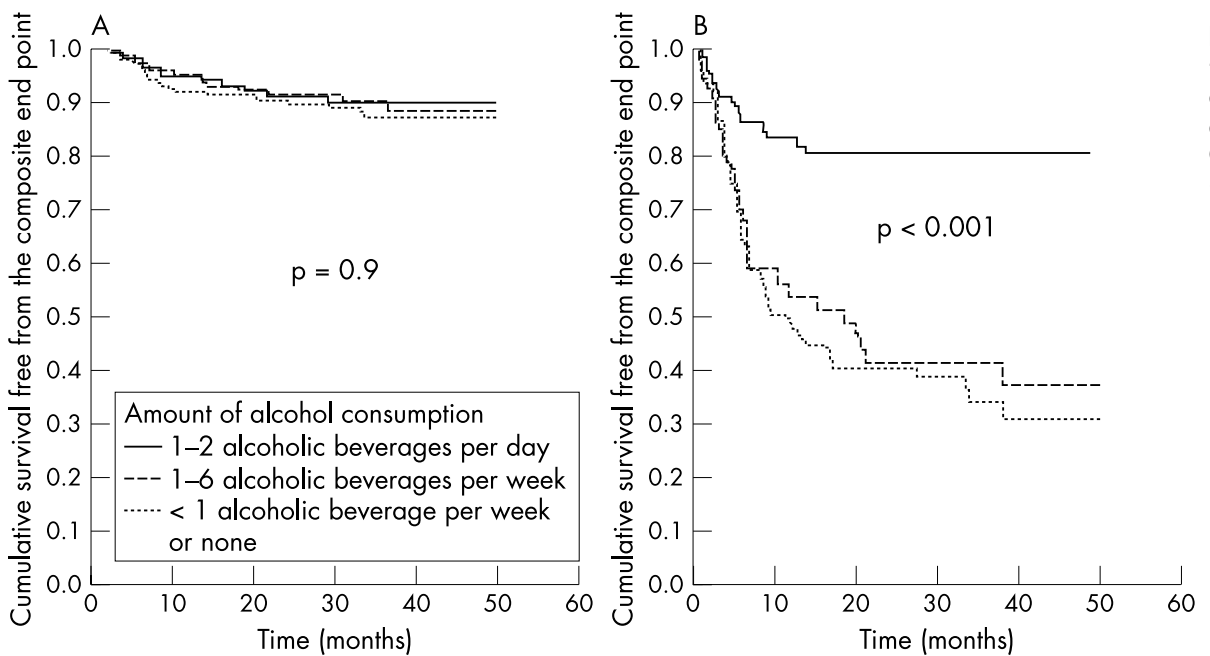

Figure 4 Kaplan-Meier curves for the four year composite primary end point among the subgroups defined by alcohol consumption in patients with CRP concentrations of $<0.68 \mathrm{mg} / \mathrm{dl}$ (A) or $\geqslant 0.68 \mathrm{mg} / \mathrm{dl}(\mathrm{B})$.

\section{DISCUSSION}

During the last several years, CRP-a sensitive and nonspecific inflammatory marker-has been extensively studied and shown to have incremental prognostic value as an indicator of short or long term coronary artery disease related ischaemic complications. ${ }^{20}{ }^{21}$ Our present substudy has shown that the value of raised plasma CRP for predicting long term ischaemic complications is consistent for up to four years after successful coronary stenting. In addition, the study showed that moderate alcohol consumption has a beneficial effect on long term prognosis following successful coronary stenting, and this effect is strongly dependent on baseline plasma CRP values. In particular, moderate alcohol consumption was associated with a reduced incidence of the composite end point or its components in patients with a baseline plasma CRP of $\geqslant 0.68 \mathrm{mg} / \mathrm{dl}$ but not in those with a value $<0.68 \mathrm{mg} / \mathrm{dl}$. These results suggest that the beneficial effect of moderate alcohol consumption on coronary artery disease related ischaemic complications may be mediated, at least in part, through an anti-inflammatory mechanism.

Previous non-randomised clinical observational studies ${ }^{22-24}$ have shown a protective effect of moderate alcohol consumption in reducing ischaemic complications in patients with coronary artery disease. It is well known that moderate alcohol consumption induces a rise in concentrations of high density lipoproteins (HDL), ${ }^{13}{ }^{15}{ }^{16}$ but a multivariate analysis has shown that only $50 \%$ of the beneficial effect of alcohol on coronary artery disease related mortality could be attributed to this effect. ${ }^{25} 26$ Other mechanisms have been proposed, such as a favourable action of moderate alcohol consumption on the haemostatic profile ${ }^{17} 18$ or possible antioxidant properties of the compounds of some drinks, but these mechanisms are not well supported. ${ }^{27-29}$ This is the first long term prospective study in patients with established coronary artery disease that suggests a possible anti-inflammatory effect ${ }^{30}$ of moderate alcohol consumption. It is also conceivable that some of the other effects of moderate alcohol consumptionincluding increases in HDL or antithrombotic effects-may lessen the impact of inflammation in patients with atherosclerosis. The precise mechanisms of this interaction are unknown.

\section{Study limitations}

Our study has limitations that must be taken into account. First, the cut off point that we used for CRP is not a generally applied value. This cut off point "optimally" dichotomised the GENERATION population for predicting the end points in our study. Second, the recently recommended high sensitivity CRP assay was not available at the beginning of the study, and was applied only in patients with values of $\leqslant 0.5 \mathrm{mg} / \mathrm{dl}$ at the first estimation. Third, only patients with successful coronary stenting were included and consequently the study findings may apply only in such patients, and should not be extrapolated to the entire coronary artery disease population. Fourth, the assessment of alcohol consumption was based on self report and this might have led to some misclassification. Fifth, the study patients did not drink the same types of beverage, even though there were no significant differences among the groups. Sixth, only average daily or weekly drinking was estimated, and issues of how and when the drinks were consumed were ignored. Seventh, drinking habits before recruitment were not assessed. Finally, this was not a randomised study, and healthier subjects were more likely to have moderate alcohol consumption. This may have introduced bias. However, there were no significant differences in baseline characteristics among the study groups, and as CRP values were not decoded before three years of follow up, no one was aware of their baseline plasma CRP levels.

\section{Conclusions}

The beneficial effect of moderate alcohol consumption on long term prognosis following successful coronary stenting may depend on the preprocedural plasma CRP concentration. An anti-inflammatory action of moderate alcohol consumption may be partly responsible for this effect, but further study is needed.

\section{Authors' affiliations}

M N Zairis, A G Lyras, M A Thoma, P K Psarogianni, P G Psaltiras, A D Kardoulas, G P Bibis, E G Pissimissis, P C Batika, A A Prekates, S G Foussas, Department of Cardiology, Tzanio Hospital, Piraeus, Greece

J A Ambrose, M C DeVoe, Department of Medicine, The Comprehensive Cardiovascular Center, Saint Vincent Catholic Medical Centers, New York, USA

\section{REFERENCES}

1 Buffon A, Liuzzo G, Biasucci LM, et al. Preprocedural serum levels of C-reactive protein predict early complications and late restenosis after coronary angioplasty. J Am Coll Cardiol 1999;34:1512-21.

2 Walter DH, Fichtlscherer S, Sellwig M, et al. Preprocedural C-reactive protein levels and cardiovascular events affer coronary stent implantation. J Am Coll Cardiol 2001;37:839-46.

3 Chew DP, Bhatt DL, Robbins MA, et al. Incremental prognostic value of elevated baseline $\mathrm{C}$-reactive protein among established markers of risk in percutaneous coronary intervention. Circulation 2001;28:974-5. 
4 de Winter RJ, Heyde GS, Koch KT, et al. The prognostic value of preprocedural plasma C-reactive protein in patients undergoing elective coronary angioplasty. Eur Heart J 2002;23:960-6.

5 Klatsky AL, Armstrong MA, Friedman GD. Alcohol and mortality. Ann Intern Med 1992;117:646-54.

6 Moore RD, Pearson TA. Moderate alcohol consumption and coronary artery disease: a review. Medicine (Baltimore) 1986;65:242-67.

7 Stampfer MJ, Colditz GA, Willett WC, et al. A prospective study of moderate alcohol consumption and the risk of coronary disease and stroke in women. N Engl J Med 1988;319:267-73.

8 Colditz GA, Branch LG, Lipnick RJ, et al. Moderate alcohol and decreased cardiovascular mortality in an elderly cohort. Am Heart J 1985;109:886-9.

9 Bradley KA, Donovan DM, Larson EB. How much is too much? Advising patients about safe levels of alcohol consumption. Arch Intern Med 1993;153:2734-40.

10 Thun JT, Peto R, Lopez AD, et al. Alcohol consumption and mortality among middle-aged and elderly US adults. N Engl J Med 1997;337:1705-14.

11 Shaper AG, Wannamethee G, Walker M. Alcohol and mortality in British men: explaining the U-shaped curve. Lancet 1988;ii:1267-73.

12 Gaziano JM, Gaziano TA, Glynn RJ, et al. Light-to-moderate alcohol consumption and mortality in the Physicians' Health Study enrollment cohort. $J$ Am Coll Cardiol 2000;35:96-105.

13 Gaziano JM, Buring JE, Breslow JL, et al. Moderate alcohol intake, increased levels of high-density lipoprotein and its subfractions, and decreased risk of myocardial infarction. N Engl J Med 1993;329:1829-34.

14 Moore RD, Smith CR, Kwiterovich PO, et al. Effect of low-dose alcohol use versus abstention on apolipoproteins A-I and B. Am J Med 1988;84:884-90.

15 Suh I, Shaten BJ, Cutler JA, et al. Alcohol use and mortality from coronary heart disease: the role of high-density lipoprotein cholesterol. Ann Intern Med 1992;116:881-7

16 Hulley SB, Gordon S. Alcohol and high-density lipoprotein cholesterol: causal inference from diverse study designs. Circulation 1981;64(suppl III): III-57-63.

17 Ridker PM, Vaughan DE, Stampfer MJ, et al. Association of moderate alcohol consumption and plasma concentration of endogenous tissue-type plasminogen activator. JAMA 1994;272:929-33
18 Renaud S, de Lorgeril M. Wine, alcohol, platelets, and the French paradox for coronary heart disease. Lancet 1992;339:1523-6.

19 Zairis MN, Ambrose JA, Manousakis SJ, et al. The impact of plasma levels of $\mathrm{C}$-reactive protein, lipoprotein (a) and homocysteine on the long-term prognosis after successful coronary stenting: the global evaluation of new events and restenosis after stent implantation study. J Am Coll Cardiol 2002;40:1375-82.

20 Danesh J, Whincup P, Walker $M$, et al. Low grade inflammation and coronary heart disease: prospective study and updated meta-analyses. BMJ 2000;321:199-204.

21 Biasucci LM, Liuzzo G, Colizzi C, et al. Clinical use of C-reactive protein for the prognostic stratification of patients with ischemic heart disease. Ital Heart $J$ 2001;2:164-71.

22 Shaper AG, Wannamethee SG. Alcohol intake and mortality in middle aged men with diagnosed coronary heart disease. Heart 2000;83:394-9.

23 Muntwyler J, Hennekens $\mathrm{CH}$, Buring JE, et al. Mortality and light to moderate alcohol consumption after myocardial infarction. Lancet 1998;352:1882-5.

24 de Lorgeril M, Salen P, Martin JL, et al. Wine drinking and risks of cardiovascular complications after recent acute myocardial infarction. Circulation 2002; 106:1465-9.

25 Gordon T, Ernst N, Fisher M, et al. Alcohol and high-density lipoprotein cholesterol. Circulation 1981;64:III 63-7.

26 Pearson AT. Alcohol and heart disease. Circulation 1996;94:3023-25.

27 van der Gaag MS, van den Berg R, van den Berg H, et al. Moderate consumption of beer, red wine and spirits has counteracting effects on plasma antioxidants in middlle-aged men. Eur J Clin Nutr 2000;54:586-91.

28 Rimm EB, Klatsky A, Grobbee D, et al. Review of moderate alcohol consumption and reduced risk of coronary heart disease: is the effect due to beer, wine, or spirits. BMJ 1996;312:731-6.

29 lijima K, Yoshizumi M, Ouchi Y. Effect of red wine polyphenols on vascular smooth muscle cell function-molecular mechanism of the "French paradox". Mech Ageing 2002;123:1033-9.

30 Imhof A, Froehlich $M$, Brenner $\mathrm{H}$, et al. Effect of alcohol consumption on systemic markers of inflammation. Lancet 2001;357:763-7.

\section{IMAGES IN CARDIOLOGY}

\section{Magnetic resonance angiography in an adult with aortic coarctation associated with subclavian stenosis}

\begin{abstract}
A 60 year old man was referred for diagnostic evaluation of severe right arm hypertension and suspected aortic coarctation. Hypertension and a systolic murmur were diagnosed when he was 20 years old. The patient suffered from a stroke a few months before admission. Physical examination revealed a grade $3 / 6$ systolic murmur at precordium radiating to the mid back, and weak and delayed femoral pulses. Blood pressure was $185 / 90 \mathrm{~mm} \mathrm{Hg}$ in the right arm and 130/75 $\mathrm{mm} \mathrm{Hg}$ in the left arm. The chest $x$ ray revealed rib notching caused by congestive collateral circulation. Thoracic magnetic resonance (MR) angiography demonstrated an extreme coarctation at the isthmus of the aorta, and a tight ostial stenosis at the origin of the left subclavian artery originating from the stenotic segment. The left internal mammary artery appeared hypertrophic and tortuous (left panel). Catheterisation showed a mean pressure gradient of $60 \mathrm{~mm} \mathrm{Hg}$ across the coarctation. Angiography confirmed the MR diagnosis (right panel).
\end{abstract}

L Fiocca, F Zumbo, A S Montenero, J D Tesoro-Tess luigifiocca@yahoo.com
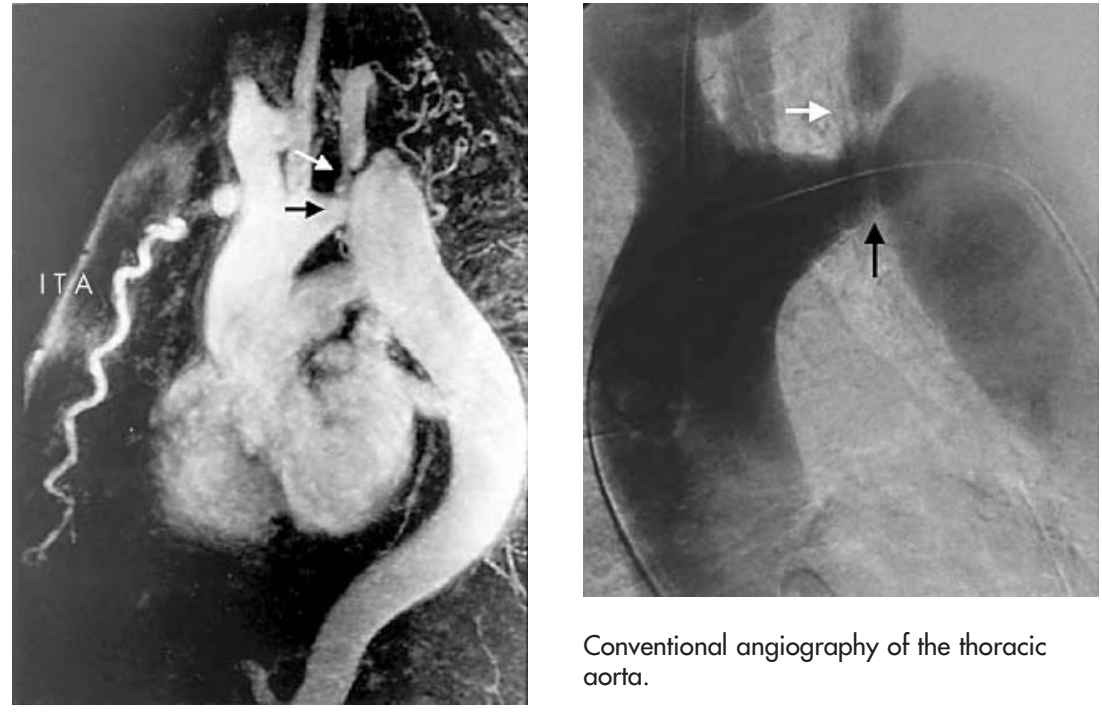

Conventional angiography of the thoracic aorta.

Gadolinium enhanced three dimensional breath hold MR angiography of the thoracic aorta. Black arrow indicate isthmic coarctation white arrow indicate left subclavian artery stenosis; ITA indicates internal thoracic artery. 